\title{
Nocardia Intramuscular Abscess in an Elderly Patient
}

\author{
Hitoshi Kuroda ${ }^{1}$, Hitoshi Sugawara ${ }^{2}$, Akira Ishii ${ }^{2}$ and Shunsuke Funazaki ${ }^{3}$
}

Key words: nocardiosis, intramuscular abscess, Gram-staining, immune status

(Intern Med 55: 2743-2744, 2016)

(DOI: 10.2169/internalmedicine.55.7044)
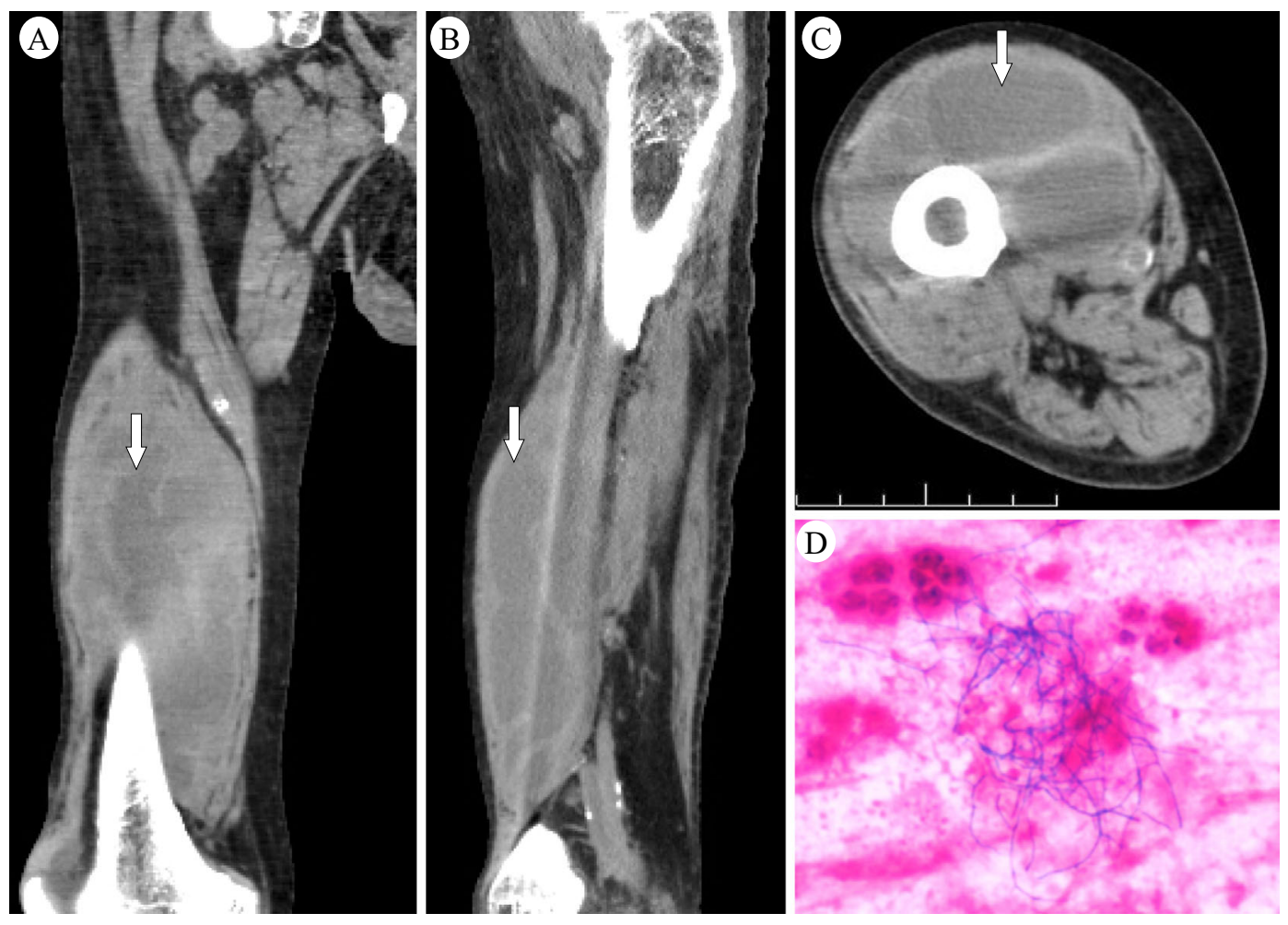

Picture.

An 84-year-old man was admitted with a fever. His treatments included medications for diabetes for over 30 years, insulin injection after steroid therapy for polymyalgia rheumatica for nine months, and voriconazole for pulmonary aspergillosis for three months.

Right thigh computed tomography detected intramuscular low-density lesions with rim thickness (Picture A-C). Cream-colored discharge by ultrasound-guided aspiration suggested intramuscular abscesses. Gram-staining revealed filamentous Gram-positive bacilli (Picture D), suggesting Nocardia. After administering nocardiosis-specific treatment, the patient recovered from his symptoms. The dischargeculture of Nocardia sp. and the antimicrobial susceptibility tests results were subsequently reported.

Nocardiosis is an opportunistic infectious disease affecting immunosuppressed patients $(1,2)$. As microbial tests for $\mathrm{No}$ cardia are time-consuming, morphological findings from Gram-staining are valuable for the initial diagnosis. This case emphasizes the importance of reference to Gramstaining for antimicrobial therapy, and the assessment of the patient's immune status.

\footnotetext{
${ }^{1}$ Department of Education and Support for Regional Medicine, Tohoku University Hospital, Japan, ${ }^{2}$ Division of General Medicine, Department of Integrated Medicine 1, Saitama Medical Center, Jichi Medical University, Japan and ${ }^{3}$ Division of Endocrine \& Metabolism, Department of Integrated Medicine 1, Saitama Medical Center, Jichi Medical University, Japan

Received for publication December 27, 2015; Accepted for publication February 3, 2016

Correspondence to Dr. Hitoshi Kuroda, qurodaj98@yahoo.co.jp
} 
The authors state that they have no Conflict of Interest (COI).

\section{References}

1. Wilson JW. Nocardiosis: updates and clinical overview. Mayo Clin Proc 87: 403-407, 2012.

2. Malani AK, Gupta C, Weigand RT, Gupta V, Rangineni S. Thigh abscess due to Nocardia farcinica. J Natl Med Assoc 98: 977-979, 2006.

The Internal Medicine is an Open Access article distributed under the Creative Commons Attribution-NonCommercial-NoDerivatives 4.0 International License. To view the details of this license, please visit (https://creativecommons.org/licenses/ by-nc-nd/4.0/).

(C) 2016 The Japanese Society of Internal Medicine http://www.naika.or.jp/imonline/index.html 